\title{
Pulmonary Function Testing Coming of Age for the Elderly
}

Since the early days of respiratory care, known then as inhalation therapy, technicians and therapists have been called upon to measure pulmonary function values in patients of all ages. In 1975, Ruppel published his first Manual of Pulmonary Function Testing ${ }^{1}$ (now in its 10th edition), making it easier for students, educators, and therapists to learn, teach, and practice, using standardized procedures. Since then, textbooks have been published that dealt specifically with pediatric PFTs ${ }^{2}$ and infant PFTs. ${ }^{3}$ In this issue of Respiratory Care, Haynes ${ }^{4}$ addresses a PFT demographic that has often been overlooked: the elderly. Dr Tom Petty stated that "pulmonary function testing (PFT) represents the most available and most practical tool in obstructive airway disease." ${ }^{5}$ Petty also went on to say that PFTs were sadly underutilized by the medical community in regards to the elderly, which contributed to delay and/or absence of a diagnosis in older adults. ${ }^{5}$ There has been a presumption over the years that older adults might not be able to adequately perform the breathing maneuvers needed to generate acceptable PFTs. This conjecture is not necessarily invalid, as age-related changes in physiology do include loss of elasticity and loss of muscle strength. However, research like that done by Haynes tells a different story.

See the Original Study on Page 16

Changes in technology and training in the past decades have most likely contributed to better PFT data collection, regardless of the patient's age. Newer devices that provide precise measurements of flow and volume have helped generate more accurate and reproducible tracings. Training of respiratory therapists has also improved. The National Board for Respiratory Care Certified Pulmonary Function Technologist (CPFT) and Registered Pulmonary Function Technologist (RPFT) credentials are desirable and in some cases mandatory for therapists who work in a PFT lab. Borg et al have also added research that can improve the collection of PFT data. ${ }^{6}$ They determined that published spirometry acceptability and repeatability could be improved and maintained when PFT labs implemented a spirometry-training program. This included regular review, feedback, and the use of a quality rating scale. This is something all PFTs labs could adopt.
Are all patients capable of performing PFTs? The answer, of course, is no. Patients/individuals with severe cognitive impairment or apraxia, of any age, may have difficulty following directions and generating meaningful PFT data. Of interest is a paper published in 2009 that measured airway resistance in older adults $(>50)$ with mild and moderate intellectual disability. Using the MicroRint airway resistance meter (CareFusion, San Diego, California) (which uses the interrupter technique), the feasibility, repeatability, and reproducibility of measuring airway resistance were good in this population. ${ }^{7}$ To presume that all older adults fall into the category of impaired intellectual ability, however, is doing a huge disservice to a rapidly expanding elderly population, many of them current and/or former smokers, and many in need of an accurate diagnosis.

Haynes's research focuses on 2 separate lung function tests: spirometry and the diffusing capacity of the lung for carbon monoxide. In order to diagnose obstructive or restrictive disease, the patient must perform both tests. Haynes's research was well thought out and the results are noteworthy. When comparing a cohort of younger adults (median age 46) to a cohort of older adults (median age 83 ), the percent of high quality tests performed by the 2 groups was no different.

Although Haynes's paper may be of interest primarily to therapists who perform PFTs, the implications are far more global in nature. These data should be used to promote and encourage physicians to appreciate the need for good quality pulmonary function studies in older adults. The population of older adults is going to continue increasing for the next $12-15$ years. ${ }^{8}$ The necessity of an accurate diagnosis and optimal treatment prescribed to patients with chronic obstructive or restrictive disease has never been greater. Regulations concerning readmission of COPD patients (from the Centers for Medicare and Medicaid Services and the Hospital Consumer Assessment of Healthcare Providers and Systems) ${ }^{9}$ mandate a more global approach to diagnosis and disease management. Based on the results of Haynes's study, elderly patients referred to a hospital-based PFT lab can be expected to achieve spirometry and diffusing capacity of the lung for carbon monoxide quality scores comparable to those of younger adults. PFTs in the elderly have "come of age" and are an excellent tool in the quest for better diagnoses, better therapeutic management, and bet- 
ter patient care. It is now up to respiratory therapists to spread the word and campaign for changes in ordering practices.

\section{Helen M Sorenson MA CPFT RRT FAARC}

Associate Professor (Retired)

Department of Respiratory Care, University of Texas Health Science Center

San Antonio, Texas

\section{REFERENCES}

1. Ruppel GL. Manual of pulmonary function testing. St Louis: Mosby; 1975.

The author has disclosed no conflicts of interest.

Helen M Sorenson MA CPFT RRT FAARC, Department of Respiratory Care, University of Texas Health Science Center, 7703 Floyd Curl Drive, MC6248, San Antonio TX 78229-3900. E-mail: sorenson@uthscsa.edu.

DOI: $10.4187 /$ respcare.02936
2. Hammer J, Eber E, editors. Paediatric pulmonary function testing. Progress in Respiratory Research, volume 33. Basel, Switzerland: Karger; 2005.

3. Stocks J, Sly PD, Tepper RS, Morgan WJ. Infant respiratory function testing. Philadelphia: John Wiley \& Sons; 1996.

4. Haynes JM. Pulmonary function test quality in the elderly: a comparison with younger adults. Respir Care 2014;59(1):16-21.

5. Petty TL, Seebass JS, editors. Pulmonary disorders of the elderly: diagnosis, prevention and treatment. Philadelphia: ACP; 2007.

6. Borg BM, Hartley MF, Bailey MJ, Thompson BR. Adherence to acceptability and repeatability criteria for spirometry in complex lung function laboratories. Respir Care 2012;57(12):20322038.

7. Pouls KP, Alsema LE, van der Laan H et al. Microrint pulmonary function testing in older adults with an intellectual disability. Respir Med 2009;103(12):1954-1959.

8. Department of Health and Human Services; Administration on Aging. Aging statistics. http://www.aoa.gov/Aging\%5FStatistics. Accessed November 4, 2013.

9. Centers for Medicare \& Medicaid Services. Readmissions reduction program. http://www.cms.gov/Medicare/Medicare-Fee-forService-Payment/AcuteInpatientPPS/Readmissions-ReductionProgram.html. Accessed November 4, 2013. 